\title{
Affective analfabeism in adolescents and their consequences for organizations
}

DOI: $10.46932 / \mathrm{sfjdv} 2 \mathrm{n} 2-041$

Received in: january 1st, 2020

Accepted in: March 30th, 2020

Kelly Danelli dos Passo

Pós-Graduação Centro Universitário La Salle - Brasil

Marcia Maria Schadd

Pós-Graduação Centro Universitário La Salle - Brasil

Marisa Claudia Jacometo Durante

Psicopedagoga Clínica e Institucional - Brasil

Paulo Renato Foletto

Pró-Reitor Administrativo Centro Universitário La Salle - Brasil

E-mail: paulo.foletto@unilasallelucas.edu.br

\begin{abstract}
Affectivity and love can build a relationship, where, through their development, one can learn the art of living together as brothers. The overall objective was to identify what consequences affective illiteracy causes for organizations. A total of 2,100 adolescents aged 15 to 17 participated. The results point to $23 \%$ of adolescents who can not feel or develop all the aspects necessary to be affective and as a consequence have a positive interpersonal relationship. It is considered that the posture of adolescents inserted in the context of affective illiteracy will influence the coexistence with the other, making difficult the work in team and the communication.
\end{abstract}

Keywords: affective illiteracy, impact on organizations, adolescents.

\section{INTRODUCTION}

People management consists of methods that seek to work on aspects related to intellectual capital, that is, people. It is used in organizations from attraction, retention, and talent development, where through good management one tries to make interpersonal relationships flow in perfect harmony.

Affectivity and love can build a relationship, where, through their development, one can learn the art of living together as brothers. The adoption of the pedagogy of educating through love could bring a positive incorporation in the social and collective life of children and adolescents. In this way, more importance would be given to coexistence with the other, which could make it easier for signs of affective illiteracy to cease to exist.

Also taking into consideration that these adolescents will enter the job market in the future, and that it is the responsibility of People Management to seek the appropriate profile for the position to be filled, through the research it was also possible to know the profile of future employees of the 
organizations that People Management will have available to recruit, select, and develop, remembering that a good interpersonal relationship is also essential to work in any organizational department.

However, analyzing empirically the society in which we live, we realize that many children already grow up frustrated for not having an interpersonal relationship with their families, the dialogue, the respect, the love and affection required. They get to school and, due to their social, physical or cultural condition, they are not accepted in the group, and end up suffering some kind of bullying, which can lead to psychological disorders.

News websites, police reports, and newspaper headlines show us that the problem of criminality involving minors is getting worse, however, it is not restricted only to families that survive in misery, but also to those that do not suffer from this evil, and one reason why this happens is the permissiveness of the parents, who do not set limits.

The general objective of the study was to identify what consequences affective illiteracy causes to organizations. Specifically, it was intended to: a) identify whether adolescents are inserted in the context of affective illiteracy; b) study the impact of affective illiteracy for organizations

Affective illiteracy can originate initially in the family, where there is no affective relationship, no hug or kiss between them. It can extend to the group of friends and colleagues, where virtual relationships often prevail and do not allow a hug or a handshake to show affection.

In this context, the research contributed for society in general to become aware that the practice of affective interpersonal relationships should start in the family and in the school with educators, encouraging them to show the other more companionship and solidarity, so that we can build a less violent, more loving, fair and egalitarian society.

\section{METHOD}

The approach taken in this study was the inductive method, and qualitative research, because, based on the research carried out, we tried to generalize the results. It was also understood that this was the best way to present the results. The method used was the case study, because a group of adolescents between 15 and 17 years of age was studied.

The research classification was exploratory, since no publication on the subject of affective illiteracy was found.

The technical procedure was a case study, since the age group of 15 to 17 years was studied.

\section{PARTICIPANTS}

The research subjects were 2,100 (two thousand and one hundred) adolescents from 15 to 17 years old, randomly chosen in public and private schools in the city of Lucas do Rio Verde - MT. 
The characterization of the subjects was obtained through the questionnaire, which had the authorization signed by the parents of the free consent form, as well as meets the Resolutions of the National Health Council No. 466/2012 regarding research with human beings and No. 251 of 07/08/97, duly approved by the Ethics Committee of the IES.

Among those surveyed, $68.6 \%$ are female and $31.4 \%$ are male. $14.3 \%$ were 15 years old, $31.4 \%$ were 16 years old, and $54.3 \%$ were 17 years old. Of these, $11.4 \%$ are in their 1 st year of high school, $27.1 \%$ are in their 2nd year of high school, and $61.4 \%$ are in their 3rd year of high school. Of the survey participants $61.4 \%$ attend public school and $38.6 \%$ attend private school. $27.1 \%$ live in rented houses and $72.9 \%$ in their own homes. $87.2 \%$ of the respondents live between 3 and 5 people in the residence. The family salary income of $58.6 \%$ of the adolescents is between $R \$ 1,301.00$ and $R \$ 5,200.00$, and according to $37.1 \%$ of the research participants the income is between $\mathrm{R} \$ 5,201.00$ and $\mathrm{R} \$ 10,000.00$.

\section{PROCEDURES}

The data was tabulated in the Sphinx program, where similar and divergent answers were separated, and from the similar and divergent answers, we performed the corresponding analysis, based on the literature review.

\section{RESULTS AND DISCUSSION}

\subsection{INSERTION OF ADOLESCENTS FROM THE AGE GROUP OF 15 TO 17 IN THE CONTEXT OF} AFFECTIVE ILLITERACY

In order to identify if the adolescents between 15 and 17 years of age are inserted in the context of affective illiteracy, we questioned when they are able to achieve the feeling mentioned by Crivelaro; Takamori (2005 p. 35) "affectivity, [...], is a feeling that arises when we spontaneously worry about the other, when we talk knowing how to listen, when we approach each other generating mutual knowledge". $48.6 \%$ of the adolescents answered that they manage to achieve this feeling most of the time, $30 \%$ sometimes, $20 \%$ always, and $1.4 \%$ never.

It can thus be seen that the $20 \%$ of adolescents who can demonstrate the feeling of affection mentioned by Crivelaro; Takamori (2005) and the $48.6 \%$ who can most of the time, are adolescents who have good interpersonal relationships and can show affection for others, because the authors also mention that the affectionate person is more likely to get internal acceptance from the other, the commitment. Affection, affection, is instinctive love. Instinctive love does not make us passionate. It just is, simply exists, and waits to be discovered to give warmth and health to our lives. It is love, the affection that endures through time, to maintain, heal and sustain the human family. 
However, the $30 \%$ of adolescents who can only sometimes express the feeling of affection, have a greater tendency not to have a positive interpersonal relationship. And the adolescent who never manages to show in his relationship with the other the feeling of affection, will hardly have a positive interpersonal relationship and will be accepted internally by the other, especially if we also analyze that Crivelaro; Takamori (2005) mention affection as one of the main psychological factors to have an adequate relationship.

Also, in order to verify if the adolescents are inserted in the context of affective illiteracy, we asked what their preference is in contact with the other, and $88.6 \%$ prefer face-to-face contact and $11.4 \%$ prefer virtual contact (using applications).

Through the answers it can be seen that most adolescents prefer face-to-face contact, which facilitates the demonstration of the feeling of affection, because according to Crivelaro; Takamori (2005) affection is also the handshake and the affectionate hug, something that is only possible through interpersonal contact. Thus, the $11.4 \%$ of adolescents who prefer virtual contact will not be able to show this affection through a machine.

Also, in order to verify if the adolescents between 15 and 17 years old are inserted in the context of affective illiteracy, we asked how many times a day they hug and/or receive a hug from their parents or people who live with them, and the majority, 32.9\%, answered none.

According to Crivelaro; Takamori (2005) affection is also shown through the handshake and the affectionate hug, in this way, if we relate it to the answer of most of the adolescents, it is possible to say that they do not show affection through this characteristic, which many times in life is necessary, because it transmits love, affection, care, and dedication. On the other hand, the rest of the teenagers surveyed are able to show or receive this affection, with $27.1 \%$ up to three times a day, which can be considered great.

To better evaluate, we also asked if the adolescents consider that they receive the love and affection they would like, regardless of who it is, and $40 \%$ answered sometimes, $30 \%$ answered most of the time, $27.1 \%$ answered always, and $2.9 \%$ answered never.

It can thus be said that most adolescents believe that they only sometimes receive the love and affection they want, which may cause them not to express as much love and affection. The $27.1 \%$ who believe they always receive it and the $30 \%$ who believe they receive it most of the time tend to offer more, and the $2.9 \%$ who never receive the love and affection they would like tend to feel excluded, which makes it difficult for them to express their feelings to others.

Also, in order to verify the insertion of adolescents in the context of affective illiteracy, we also asked if the adolescents talk to other people and exchange knowledge. $47.1 \%$ answered that most of the time, $31.4 \%$ answered sometimes, and $21.4 \%$ answered always, and no adolescent answered never. 
Therefore, it can be seen that most adolescents talk to other people exchanging knowledge and can show affection this way, because the authors Crivelaro; Takamori (2005) state that affection is also a feeling that occurs when we approach each other generating mutual knowledge. However, the $31.4 \%$ who only talk sometimes, exchanging knowledge, are not able to show as much affection compared to the others.

Seeking more information to verify the insertion in the context of affective illiteracy, we asked the adolescents if they usually have some kind of conflict with other people, and the majority, $71.4 \%$ answered sometimes, $14.3 \%$ answered never, $8.6 \%$ most of the times, and $5.7 \%$ always.

From the answers, we can see that only $14.3 \%$ of the adolescents do not have conflicts with other people, and all the others, even if in different proportions, usually have some kind of conflict. In fact, in certain situations conflict can be positive, but when it becomes routine, it can cause problems for social coexistence, and according to Crivelaro; Takamori (2005), instinctive love and affection must endure between people, because it is the same that sustains the human family, and can maintain harmonious social coexistence.

We asked several questions regarding the frequency with which they feel emotions, based on the author Golemam (2007) who defines them as the main candidates of emotions and members of their families.

Thus, we asked how often adolescents in their personal life and in their relationship with other people feel fear as described by Golemam (2007) fear: anxiety, apprehension, nervousness, worry, consternation, caution, scruples, uneasiness, dread, fright, terror, and as psychopathology, phobia and panic. The following results were obtained: $62.9 \%$ sometimes, $15.7 \%$ often, $12.9 \%$ frequently, and $8.6 \%$ never.

Through the results, it is possible to notice that most adolescents feel fear according to the definition by Golemam (2007), sometimes, followed by many times and often, and after a small number of adolescents who never feel this emotion, thus assessing that in adolescents where this emotion is more consistent, some kind of affective support may be lacking, which in a way facilitates their insertion in the context of affective illiteracy.

As a complement, we questioned how often in their personal life and in their relationship with other people do the adolescents feel sadness, according to the definition by Golemam (2007) sadness: suffering, sorrow, discouragement, discouragement, melancholy, self-pity, loneliness, helplessness, despair, and when pathological, severe depression. Most of the adolescents, $65.7 \%$, answered sometimes. 
Thus, evaluating the results it can be seen that almost all the adolescents surveyed feel sadness at some point in their personal lives and in their relationships with other people, with only $14.03 \%$ never feeling it.

Thus, it is considered that the consistency of this type of emotion can be caused by affective deprivation, and in adolescents where it is more consistent, there is a greater likelihood of falling within the context of affective illiteracy. And yet, according to Castro (2014) this emotion can compromise the psychological well-being and consequently the performance and performance of the human being.

In order to better evaluate, we also questioned how often adolescents in their personal lives and in their relationships with other people feel pleasure according to Golemam's (2007) definition of pleasure: happiness, joy, relief, contentment, delight, amusement, pride, sexual pleasure, excitement, rapture, gratification, satisfaction, euphoria, ecstasy, and, in the extreme, mania. The majority of the adolescents, $40 \%$ answered often, followed by $38.6 \%$ often and then $21.4 \%$ sometimes.

It is perceived through the results that most of the adolescents feel pleasure many times and soon followed by often, as described by Golemam (2007). It is thus evaluated that adolescents who feel this emotion more consistently tend to feel good and transmit this to other people which will positively influence their interpersonal relationships, and furthermore according to Castro (2014) this emotion still acts as a powerful motivator, positively influencing the physical, mental, and spiritual health of people.

We also questioned how often in their personal lives and in their relationships with other people, adolescents feel love according to Golemam's (2007) definition of love: acceptance, friendship, trust, affinity, dedication, adoration, passion, agape. The results show that $47.1 \%$ of the adolescents feel love often, $28.6 \%$ often, $21.4 \%$ sometimes, and $2.9 \%$ never.

The results show that most adolescents feel the love described by Golemam (2007), which can be the result of an adequate interpersonal relationship, which is achieved through the use of the three main psychological motivators mentioned by Crivelaro; Takamori (2005), which are self-esteem, empathy, and affection.

However, there are $21.4 \%$ who feel this emotion sometimes and $2.9 \%$ never, which can be explained by the lack of some or all of the psychological motivators cited by the authors to have an adequate relationship, evaluating that the feeling of love is caused by acceptance, friendship, dedication, etc., which are found in self-esteem, empathy, and affectivity.

Thus, adolescents in whom the emotion of love as defined by Golemam (2007) is less consistent are more likely to have negative relationships than those who can feel love more consistently.

Seeking more information, we asked the adolescents how often in their personal lives and in their relationships with other people they feel shame as defined by Golemam (2007) shame: guilt, vexation, 
grief, remorse, humiliation, regret, mortification, and contrition. The majority, $77.1 \%$ of the adolescents answered sometimes, $10 \%$ answered never, $8.6 \%$ answered often, and $4.3 \%$ answered frequently.

The results show us that most of the adolescents surveyed have felt shame at some point in their personal lives and in their relationships with other people, and only $10 \%$ have never felt shame. According to Golemam's definition (2007), it can be inferred that adolescents who feel this emotion more consistently tend to be more successful in interpersonal relationships, because they are aware of their attitudes, but those who do not have this feeling may not be successful in interpersonal relationships, because they are too proud to admit that they can also make mistakes, and thus may be more prone to fall into affective illiteracy.

In our conception, affective illiteracy is the absence of a positive interpersonal relationship, of a relationship of instinctive love, friendship and solidarity, a handshake and/or a warm hug, a spontaneous feeling of concern for the other, when one talks knowing how to listen, when one gets close generating mutual knowledge.

Considering this conception, it can be noticed that most of the teenagers surveyed, in the age group of 15 to 17 years old, manage to develop the feeling of affectivity, self-esteem, and empathy, which makes them develop a positive relationship, making them less prone to insertion in the context of affective illiteracy.

However, it can be said that there is a minority of adolescents, in the age group of 15 to 17 years old, among those surveyed, who cannot feel and develop all the necessary aspects to be affective and, as a consequence, to have a positive interpersonal relationship. Thus, it is possible to infer that this minority of adolescents is inserted in the context of affective illiteracy.

\subsection{IMPACT OF AFFECTIVE ILLITERACY FOR ORGANIZATIONS}

In order to study the impact of affective illiteracy on organizations, we sought information about the profile of adolescents between the ages of 15 and 17 who will be part of the labor market in the future.

Also, with the purpose of studying the impact of affective illiteracy for organizations, we asked the adolescents between 15 and 17 years old how they understand the work environment, and with greater representation, $27.1 \%$ answered that they understand the work environment as a very busy place, that one must take seriously and have a lot of dedication, professionalism, companionship, responsibility, friendship, focus, concentration, and understanding; $12.8 \%$ answered that they understand the work environment as a place of commitment, where one puts knowledge into practice, learns, and always seeks to improve, gets to know and interacts with people; $7.1 \%$ answered that they understand the work environment as a pleasant and pleasant environment, where there must be respect. 
Through the adolescents' understanding of the work environment, it can be noticed that they have a good perception of how it should be. Thus, it is based on this understanding that the adolescents will act when they are working in the job market.

To better evaluate, we asked how the adolescents imagine the relationship with others in the work environment, and with a greater representation, $24.2 \%$ answered that they consider the relationship with others in the work environment to be good, with partnership and collegiality among everyone, without conflicts; $18.5 \%$ answered that they imagine the relationship with others in the work environment with respect and understanding towards each other, friendship, collaboration, and teamwork; $18.5 \%$ answered that they imagine the relationship with others in the work environment to be harmonious, pleasant, friendly, tolerable, passive, professional, and healthy.

It can be said through the answers that by imagining the relationship in the work environment with all the positive aspects mentioned, the adolescents will try to develop these characteristics and behave this way in their relationship with others in the work environment.

In an attempt to study the impact of affective illiteracy on organizations, we asked teenagers between the ages of 15 and 17 what they think about living with others. $22.8 \%$ of them think that living with others is good, that one helps the other, that one acquires new knowledge, because being happy alone is not possible; $11.4 \%$ of the adolescents think that living with others is good and necessary, it's part of life, because we have to live with people, no living being is capable of living alone, isolated; $7.1 \%$ of the adolescents think that living with others is to have mutual respect, friendship, and companionship, to know how to understand the opinions of others and express their own.

However, it is considered that adolescents think that living with the other is something good in all aspects, thus evaluating that they tend to act this way in their relationships.

However, analyzing the profile of the adolescents, based on the previous objectives, one notices that not all of them are able to act this way, which may make it difficult for them to coexist with the other in the organization they will work in the future.

Trying to understand the profile of the adolescents, when using the Sphinx program for data tabulation, a cross-referencing of information regarding salary income, with whom and how many people live in the same house, and to which school network they belong was performed; however, the program did not indicate relevant results. Thus, it is inferred that in this group these variables do not interfere in interpersonal relationships.

Therefore, relating to the previous objectives, it can be noticed that the future collaborators of the organizations, the current teenagers, have a profile linked to technology, where they need to be connected 
all the time, and patience is not a virtue, and a good relationship within an organization requires, above all, patience.

However, it was possible to notice that most of the teenagers surveyed can maintain a good relationship, but a minority is lacking one or more aspects necessary for a positive relationship with the other, which makes them fall into the context of affective illiteracy.

Thus, it can be said that the attitude of adolescents within the context of affective illiteracy will influence the coexistence with others within the organization, impacting on greater conflicts with colleagues, hindering teamwork and communication. Considering this, adolescents who fit into the context of affective illiteracy may harm their own professional performance and as a consequence the organization's performance.

\section{FINAL CONSIDERATIONS}

Considering the study, it can be inferred that most adolescents in the age group of 15 to 17 years old have a perception that affectivity is necessary to maintain a good relationship, demonstrated through the feeling of spontaneous concern with the other, the exchange of knowledge and experiences, the affectionate hug, in short, the affection that an individual needs in order not to feel rejected or excluded, both by family, friends, and even by society.

On the other hand, it was also noticed that there is a minority of adolescents between 15 and 17 years old who cannot fully demonstrate the feeling of affection, leading us to understand that they do not have a perception of the real meaning of affection, nor the importance of this feeling for people's lives.

However, it can be said that the results of the study showed positive and negative points about the positive relationship with the other, but it is still possible to reverse the negative points by developing the three main psychological motivators: self-esteem, empathy, and affectivity, and also emotional intelligence.

Analyzing the results of the research with adolescents between 15 and 17 years old, it was observed that the theory studied reflects in practice, where through the citations of several authors it was possible to reach considerations with theoretical basis about the feelings and emotions of adolescents.

From the study, it was also obtained a perception that the adolescents who manage to develop the necessary aspects for an adequate relationship will achieve greater success, both in personal and professional relationships.

However, it was also noticed that the teenagers surveyed fit into the $\mathrm{Z}$ generation, where they were born into a technological world, and cannot stay disconnected. It is considered that this, in the same way 
that it can facilitate communication, can also harm their interpersonal relationships, affectivity, and in the future their performance within the organization they will work for.

In this way, it is suggested that the adolescents themselves try to become self-aware, monitoring and controlling themselves so that this need to be connected at all times does not harm them in their social, professional, and emotional lives.

However, this study contributes for society in general to realize the importance of affection in people's lives, and to become aware that if feelings of affection are developed and worked on positively from the beginning of life, starting with the family, there will be a greater probability of positive relationships that will contribute to the success of the individual and to harmonious social coexistence. 


\section{REFERENCES}

Castro, J. (2014). Positive and negative emotion. Retrieved from http://www2.uol.com.br/JC/sites/deloitte/artigos/a107.htm.

Crivelaro, R. \& Takamori, J. Y. (2005) Dynamics of interpersonal relationships. Campinas/SP: Editora Alinea.

Golemam, D. (2007) Inteligência Emocional: a teoria evolucionária que define o que é ser inteligente. Rio de Janeiro: Objetiva. 